\title{
Pulmonary arterial hypertension associated with congenital heart disease after defect repair: the effect of pregnancy
}

\author{
Margarita Brida', Carla Favoccia', Andrew Constantine ${ }^{1,2}$ and Konstantinos Dimopoulos ${ }^{2,3^{*}}$ (D)
}

\begin{abstract}
Background: An increasing number of patients with previously repaired congenital heart disease (CHD) present with pulmonary arterial hypertension (PAH). This can occur immediately after repair (residual PAH) or years later.

Case presentation: We present the case of a young woman who underwent repair of a ventricular septal defect in later childhood. Three years after repair, she was found to have significant residual PAH. She remained stable on PAH therapies, but a decade later decided to become pregnant against medical advice. She deteriorated during pregnancy and required escalation of PAH therapies and eventual admission to the intensive care unit, with an uneventful delivery at 32 weeks. Despite successful delivery, she remained symptomatic post-partum, with evidence of disease progression at right heart catheterisation.

Conclusions: All patients with repaired CHD should undergo routine screening for $\mathrm{PAH}$. Early diagnosis and expert management, including the use of PAH therapies, is recommended to optimise outcome. Pregnancy is contraindicated in PAH patients, including patients with $\mathrm{CHD}$, and requires an expert multidisciplinary approach to reduce morbidity and mortality when patients opt to proceed.
\end{abstract}

Keywords: Pulmonary arterial hypertension, Congenital heart disease, Pregnancy, Caesarean section

\section{Background}

Pulmonary arterial hypertension (PAH) related to congenital heart disease (CHD) belongs to group 1 of the international classification of pulmonary hypertension $(\mathrm{PH})$, as it shares a similar pathophysiology, clinical presentation and response to therapy to other types of PAH, such as idiopathic PAH or PAH related to connective tissue disease (PAH-CHD) [1]. PAH-CHD encompasses a wide spectrum of conditions and is classified into 4 groups (see article by $\mathrm{R}$ Condliffe entitled "Pulmonary Arterial Hypertension associated with Congenital Heart Disease: Classification and Pathophysiology" in this

\footnotetext{
* Correspondence: k.dimopoulos02@gmail.com

${ }^{2}$ National Heart and Lung Institute, Imperial College, London, UK

${ }^{3}$ Adult Congenital Heart Centre, Royal Brompton and Harefield NHS Foundation Trust, Sydney Street, London SW3 6NP, UK

Full list of author information is available at the end of the article
}

issue). Group D PAH-CHD includes patients with PAH after congenital heart defect correction. In some patients, PAH may persist after surgery or intervention, typically when this is performed "late". In other patients, PAH develops months or years after repair. In the absence of a significant residual defect, patients with repaired PAH-CHD are thought to behave more like patients with idiopathic PAH than those with Eisenmenger syndrome in terms of cardiac pathophysiology and prognosis [2]. Indeed, patients with repaired PAH-CHD have been included in many studies of PAH therapy, together with idiopathic and connective tissue disease-related $\mathrm{PAH}$ [3-5]. In PAH-CHD, like in other types of PAH, pregnancy is generally associated with significant, prohibitive risks (depending on the severity of the PAH), and is contraindicated $[6,7]$. 
We present the case of a young woman with persistent $\mathrm{PAH}$ after repair of $\mathrm{CHD}$, in whom significant progression of the disease was observed during pregnancy, requiring escalation of PAH therapies.

\section{Case presentation}

This 12-year-old female presented to our tertiary cardiac centre with a diagnosis of a peri-membranous ventricular septal defect (VSD) and patent foramen ovale (PFO). As part of her initial assessment, she underwent diagnostic cardiac catheterisation. This showed a step-up in oxygen saturations from mixed venous to pulmonary artery from 74 to $85 \%$. Her mean pulmonary arterial pressure (mPAP) was $44 \mathrm{mmHg}$, with a pulmonary to systemic blood flow ratio (Qp/Qs) of 2 and pulmonary vascular resistance indexed (PVRI) of 6.5 WU.m ${ }^{2}$. Vasoreactivity testing with inhaled oxygen and nitric oxide was performed, showing an increase in Qp/Qs to 3 and decrease in PVRI to 4.8 WU.m ${ }^{2}$.

She underwent percutaneous VSD closure with a 14 $\mathrm{mm}$ Amplatzer occluder device following discussion in the adult CHD multidisciplinary team meeting. Immediately post-deployment of the device, right ventricular systolic pressure was $48 \mathrm{mmHg}$. Three years after intervention she became progressively short of breath on exertion and cardiac catheterisation was repeated. There was severe pulmonary arterial hypertension with a PVRI of 13.4 WU.m ${ }^{2}$ and a relatively small drop in PVRI with nitric oxide, to 8 WU.m ${ }^{2}$ (Fig. 1). She was commenced on PAH therapy with an endothelin receptor antagonist, resulting in an improvement in functional status (from functional class III to II).

She remained clinically stable for several years and at the age of 24 decided to pursue pregnancy, despite repeated counselling regarding the risks. The endothelin receptor antagonist was withdrawn, and she was commenced on sildenafil (a phosphodiesterase- 5 inhibitor) and anticoagulation with therapeutic doses of enoxaparin sodium as soon as she became pregnant. She remained stable during the first half of her pregnancy, however, she presented at 23 weeks' gestation with increasing shortness of breath and pre-syncopal episodes on moderate effort. She also developed small-volume haemoptysis related to a respiratory tract infection. She was admitted to the intensive care unit for advanced monitoring and was started on intravenous epoprostenol at slowly increasing doses up to $20 \mathrm{ng} /$ $\mathrm{kg} / \mathrm{min}$ (Figs. 2 and 3). She also required respiratory support with continuous positive airway pressure (CPAP) and high-flow oxygen, as well as antibiotics. She remained relatively stable and underwent uneventful elective Caesarean section at 32 weeks of pregnancy, having a healthy baby boy.

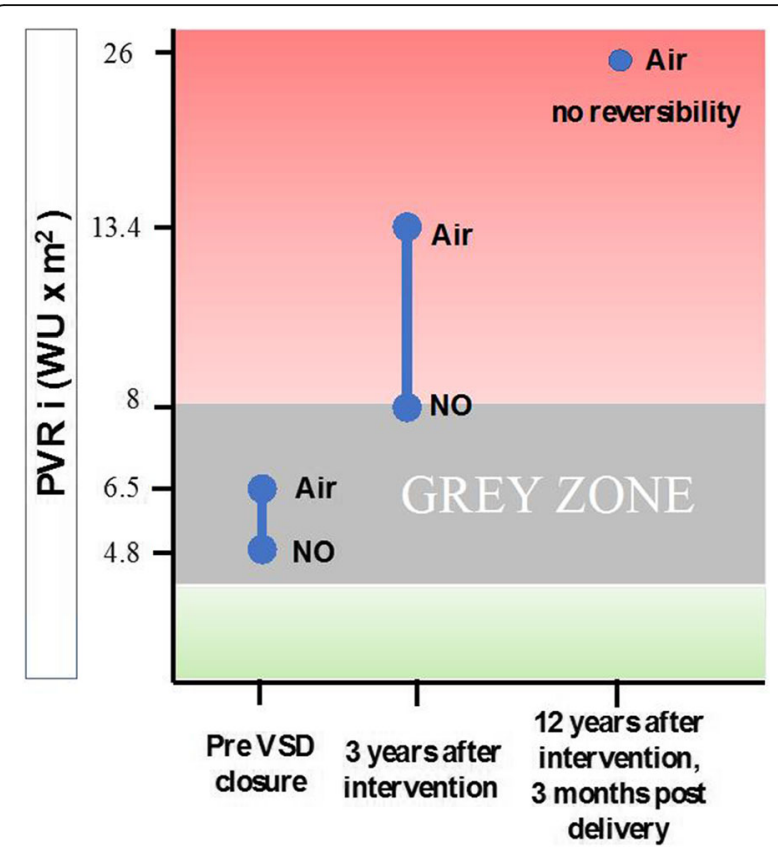

Fig. 1 Cardiac catheterisation data: On presentation (left), the cardiac catheter measured a PVRI of $6.5 \mathrm{WU} \cdot \mathrm{m}^{2}$ on air and 4.8 WU. $\mathrm{m}^{2}$ after nitric oxide (NO). The patient was therefore in the borderline "grey zone" for defect closure, according to current PH guidelines. Three years after closure of the VSD, PVRI had risen to 13.4 WU. $\mathrm{m}^{2}$, dropping to 8 WU. $\mathrm{m}^{2}$ with NO. Twelve years later, 3 months after delivery, the PVRI had doubled to 26 WU. $\mathrm{m}^{2}$ with no reversibility

She remained stable and was discharged from hospital a week after delivery on triple combination therapy with a sildenafil, macitentan (an endothelin receptor antagonist) and intravenous epoprostenol.

Three months after delivery she remained in functional class II. However, repeat right heart catheterisation showed severe PAH with a PVRI of 26 WU.m ${ }^{2}$ without reversibility (Fig. 1). She was referred for transplant assessment but was deemed to be too well for immediate listing. Eighteen months later she remains in good condition, managing to take care of her baby and remains off the active transplant list.

\section{Discussion and conclusions}

We present the case of a patient with a perimembranous VSD who underwent closure of the defect with borderline haemodynamics. According to current recommendations, a PVRI between 4 and 8 WU. $\mathrm{m}^{2}$ falls within the so-called "grey zone", i.e. not clearly operable, but without prohibitive haemodynamics [8]. Patients with borderline PVRI are a challenging group. Deciding whether the shunt should be closed is difficult and controversy remains on the merits of closing such defects [9-11]. Closing the defect has the advantage of abolishing left-right shunting and the associated load on the 


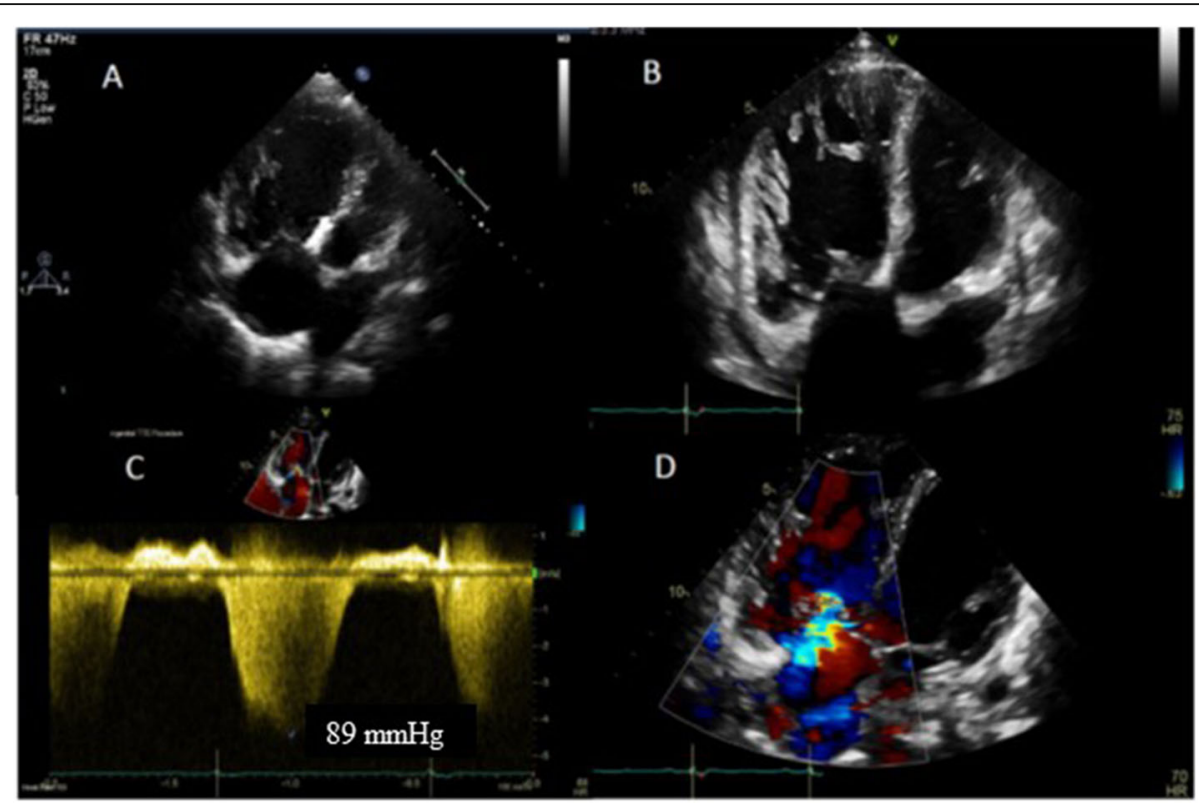

Fig. 2 Echocardiogram during the late stages of pregnancy: In $\mathbf{a}$ and $\mathbf{b}$, the right ventricle is severely dilated and forms the apex, with hypertrophy and preserved overall systolic function. The VSD closure device appears well seated in the peri-membranous region (arrow) with no obvious residual shunt. The right atrium is severely dilated. In $\mathbf{c}$ and $\mathbf{d}$, there is moderate tricuspid regurgitation (multiple jets) with an estimated right ventricular systolic pressure of $89 \mathrm{mmHg}$ plus right atrial pressure

heart and pulmonary circulation. However, in cases in which pulmonary vascular disease is present and may progress, closing a defect that may act as a relief valve for the right ventricle may prove detrimental in the long-term. Unfortunately, there is very little evidence on which to base the decision to repair defects in patients with a mild or moderate increase in PVRI. In this patient, the PVRI not only did not drop 3 years after defect closure, but increased significantly despite abolishing the ventricular shunt, an outcome that could not have been predicted based on pre-intervention haemodynamics.

Our patient decided to become pregnant despite extensive counselling with regards to the risks of pregnancy and delivery. Current evidence from systematic reviews and registries suggests that mortality and morbidity are high in PAH, despite an apparent improvement in outcome in recent years $[6,7]$. This improvement may be related to several factors including

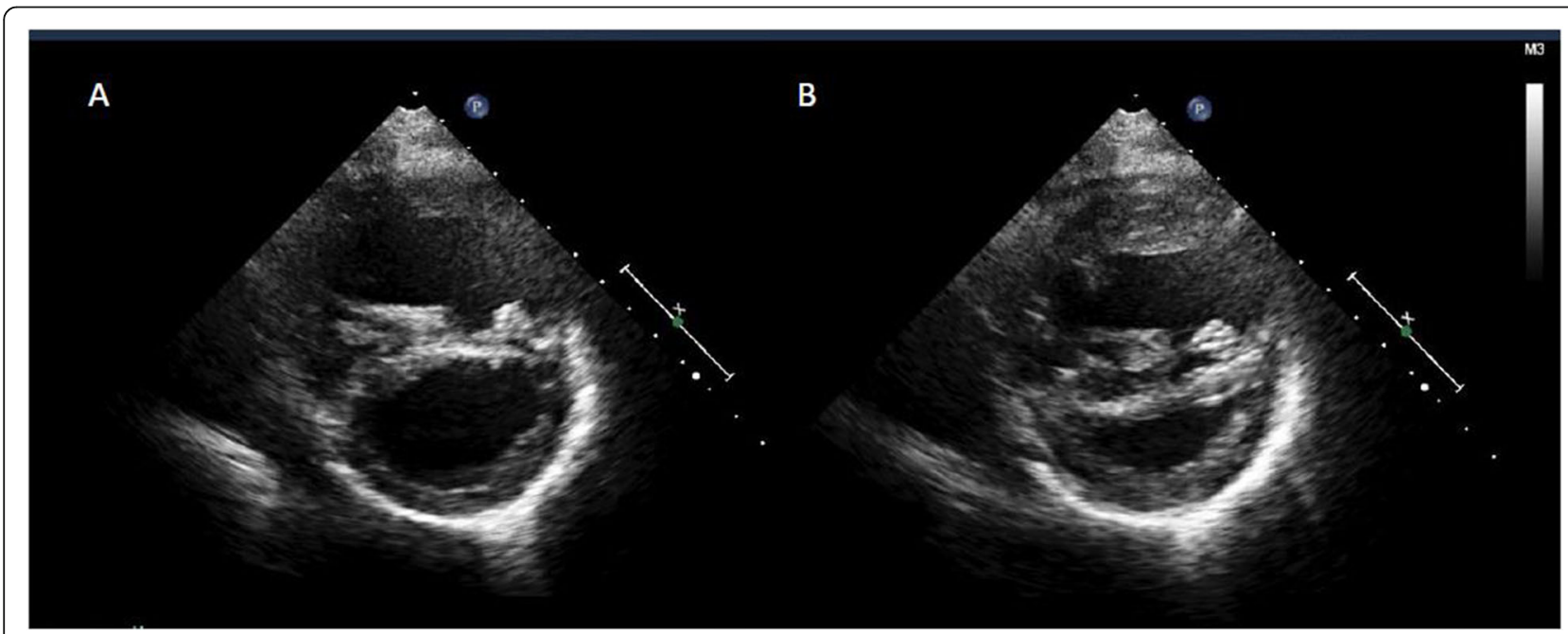

Fig. 3 Echocardiogram: There is flattening of the septum in diastole (a) and systole (b) suggestive of RV pressure overload 
aggressive use of PAH therapies and the development of multidisciplinary pregnancy and heart disease teams. However, even when PAH patients survive pregnancy, disease progression may be observed in patients who may otherwise have remained stable for many years [8].

Further studies are needed to understand how to decide on the operability of CHD patients with abnormal pulmonary haemodynamics. When such patients do undergo defect closure, close monitoring over the months and years after the operation is required, to identify those in whom pulmonary vascular disease persists or progresses. Patients with repaired PAH-CHD should be considered for PAH therapies early after diagnosis, with the aim to improve haemodynamics and outcome.

\section{Abbreviations}

CHD: Congenital heart disease; CPAP: Continuous positive airway pressure; mPAP: Mean pulmonary arterial pressure; PAH: Pulmonary arterial hypertension; PAH-CHD: Pulmonary arterial hypertension related to congenital heart disease; PFO: Patent foramen ovale; PH: Pulmonary hypertension; PVR(I): Pulmonary vascular resistance (indexed); $\mathrm{Qp} /$ Qs: Pulmonary to systemic blood flow ratio; VSD: Ventricular septal defect

\section{Acknowledgements}

Not applicable.

\section{About this supplement}

This article has been published as part of Journal of Congenital Cardiology Volume 4 Supplement 1 2020: Unmet needs in Pulmonary Hypertension associated with Adult Congenital Heart Disease (ACHD-PH). The full contents of the supplement are available at https://jcongenitalcardiology. biomedcentral.com/articles/supplements/volume-4-supplement-1.

\section{Authors' contributions}

$\mathrm{MB}, \mathrm{CF}, \mathrm{AC}$ and $\mathrm{KD}$ contributed to the planning of the manuscript. MB drafted the case study, which was then critically appraised and revised by $C F, A C$ and $K D . M B, C F, A C$ and $K D$ approved the final version of the manuscript for publication

\section{Funding}

Medical writing support was provided by nspm Itd, Meggen, Switzerland. The manuscript was funded by a Medical and Educational Goods and Services (MEGS) grant and Actelion Pharmaceuticals UK Limited (who had no influence on manuscript writing).

\section{Availability of data and materials}

Not applicable.

\section{Ethics approval and consent to participate}

The patient provided fully informed, written consent to form the subject of this case study in line with CARE guidelines. No formal ethics approval was necessary.

\section{Consent for publication}

The patient gave consent for their personal or clinical details to be published in this study. No identifying images are included.

\section{Competing interests}

Dr. Constantine has received a personal educational grant from Actelion Pharmaceuticals UK. Dr. Dimopoulos has received nonfinancial support from Actelion Pharmaceuticals; and has been a consultant to and received grants and personal fees from Actelion Pharmaceuticals, Pfizer, GlaxoSmithKline, and Bayer/MSD. The authors have no other relevant affiliations or financial involvement with any organization or entity with a financial interest in or financial conflict with the subject matter or materials discussed in the manuscript apart from those disclosed.

\section{Author details}

'Adult Congenital Heart Centre and National Centre for Pulmonary Hypertension, Royal Brompton Hospital, London, UK. ${ }^{2}$ National Heart and Lung Institute, Imperial College, London, UK. ${ }^{3}$ Adult Congenital Heart Centre, Royal Brompton and Harefield NHS Foundation Trust, Sydney Street, London SW3 6NP, UK.

Received: 12 November 2020 Accepted: 12 November 2020

Published: 16 December 2020

\section{References}

1. Authors/Task Force Members:; Galiè N, Humbert M, Vachiery J-L, Gibbs S, Lang I, Torbicki A et al. 2015 ESC/ERS Guidelines for the diagnosis and treatment of pulmonary hypertension: The Joint Task Force for the Diagnosis and Treatment of Pulmonary Hypertension of the European Society of Cardiology (ESC) and the European Respiratory Society (ERS) Endorsed by: Association for European Paediatric and Congenital Cardiology (AEPC), International Society for Heart and Lung Transplantation (ISHLT). Eur Heart J. 2016;37(1):67-119. Available from: https://doi.org/10.1093/eurheartj/ ehv317.

2. Alonso-Gonzalez R, Lopez-Guarch CJ, Subirana-Domenech MT, Ruíz JMO, González IO, Cubero JS et al. (REHAP investigators). Pulmonary hypertension and congenital heart disease: an insight from the REHAP National Registry. Int J Cardiol. 2015;184:717-723. Available from: https://doi.org/10.1016/j. ijcard.2015.02.031.

3. Jansa P, Pulido T. Macitentan in pulmonary arterial hypertension: a focus on combination therapy in the SERAPHIN trial. Am I Cardiovasc Drugs Drugs Devices Interv. 2018;18(1):1-11. Available from: https://doi.org/10.1007/ s40256-017-0260-1.

4. Rosenkranz S, Ghofrani H-A, Beghetti M, Ivy D, Frey R, Fritsch A et al. Riociguat for pulmonary arterial hypertension associated with congenital heart disease. Heart Br Card Soc. 2015;101(22):1792-1799. Available from: https://doi.org/10.1136/heartjnl-2015-307832.

5. Sitbon O, Channick R, Chin KM, Frey A, Gaine S, Galiè N et al. (GRIPHON investigators). Selexipag for the treatment of pulmonary arterial hypertension. N Engl J Med. 2015;373(26):2522-2533. Available from: https:// doi.org/10.1056/nejmoa1503184.

6. Bédard E, Dimopoulos K, Gatzoulis MA. Has there been any progress made on pregnancy outcomes among women with pulmonary arterial hypertension? Eur Heart J. 2009;30(3):256-265. Available from: https://doi. org/10.1093/eurhearti/ehn597.

7. Roos-Hesselink JW, Ruys TPE, Stein JI, Thilén U, Webb GD, Niwa K et al. (ROPAC investigators). Outcome of pregnancy in patients with structural or ischaemic heart disease: results of a registry of the European Society of Cardiology. Eur Heart J. 2013;34(9):657-665. Available from: https://doi.org/ 10.1093/eurheartj/ehs270.

8. Dimopoulos K, Wort SJ, Gatzoulis MA. Pulmonary hypertension related to congenital heart disease: a call for action. Eur Heart J. 2014;35(11):691-700. Available from: https://doi.org/10.1093/eurheartj/eht437.

9. D'Alto M, Romeo E, Argiento P, Correra A, Santoro G, Gaio G et al. Hemodynamics of patients developing pulmonary arterial hypertension after shunt closure. Int J Cardiol. 2013;168(4):3797-3801. Available from: https://doi.org/10.1016/j.ijcard.2013.06.036.

10. D'Alto M, Dimopoulos K, Coghlan JG, Kovacs G, Rosenkranz S, Naeije R. Right heart catheterization for the diagnosis of pulmonary hypertension: controversies and practical issues. Heart Fail Clin. 2018;14(3):467-477. Available from: https://doi.org/10.1016/j.hfc.2018.03.011.

11. Constantine A, Dimopoulos K. Evaluating a strategy of PAH therapy pretreatment in patients with atrial septal defects and pulmonary arterial hypertension to permit safe repair ("treat-and-repair"). Int J Cardiol. 2019;291: 142-144. Available from: https://doi.org/10.1016/j.ijcard.2019.05.039.

\section{Publisher's Note}

Springer Nature remains neutral with regard to jurisdictional claims in published maps and institutional affiliations. 